| Dossiê: Impactos e Repercussões Socioambientais de Empreendimentos na Pan-Amazônia | DOI: http://dx.doi.org/10.18764/2446-6549.e202010

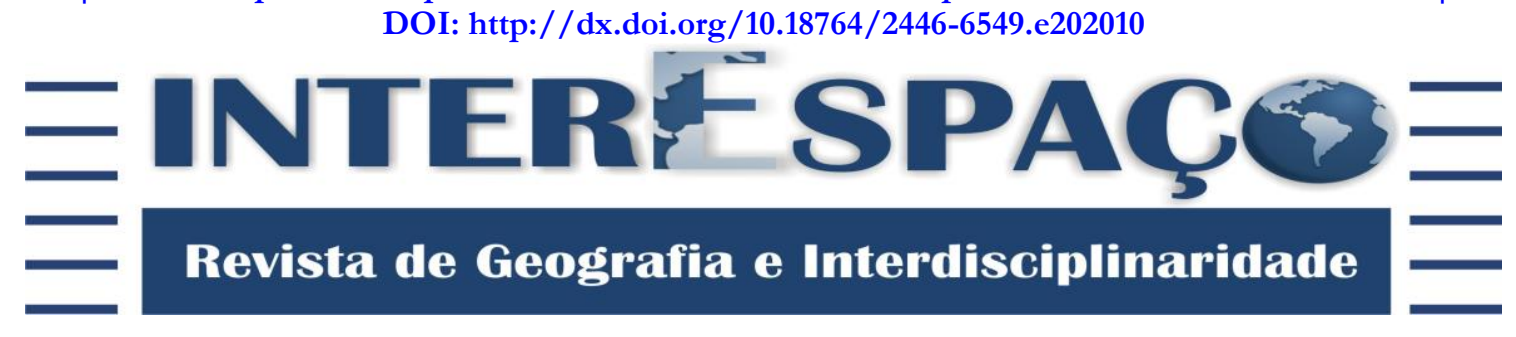

\title{
USOS E ABUSOS DOS RECURSOS HÍDRICOS PELA DENDEICULTURA NA AMAZÔNIA PARAENSE ${ }^{1}$
}

\section{USES AND ABUSES ON THE HYDRIC RESOURCES BY THE OIL PALM CULTIVATION IN THE PARÁ'S AMAZON}

\section{USOS Y ABUSOS DE LOS RECURSOS HÍDRICOS POR DENDEICULTURA EN LA AMAZONÍA PARAENSE}

\section{João Santos Nahum}

Doutor em Geografia Universidade Estadual Paulista - UNESP/Rio Claro. Docente da Faculdade de Geografia e Cartografia e do Programa de Pós-Graduação em Geografia da Universidade Federal do Pará - FGC/PPGEO/UFPA. Coordenador do Grupo de Pesquisa GDEA - Dinâmicas

Territoriais do Espaço Agrário na Amazônia e do Observatório do Dendê. prof.joaonahum@gmail.com / http://orcid.org/0000-0001-7791-9240

\section{Leonardo de Sousa Santos}

Doutor em Geografia pela Universidade Federal do Pará - UFPA. Pesquisador do Grupo de Pesquisa GDEA - Dinâmicas Territoriais do Espaço Agrário na Amazônia e Secretário do Observatório do Dendê. leonardodrgeo@gmail.com / http://orcid.org/0000-0003-1912-7100

\section{Cleison Bastos dos Santos}

Doutor em Geografia pela Universidade Federal do Pará - UFPA. Professor da Secretaria Municipal de Educação de Moju e da Secretaria Executiva de Educação do Estado do Pará - $3^{a}$ URE. Pesquisador do Grupo de Pesquisa GDEA - Dinâmicas Territoriais do Espaço Agrário na Amazônia e Coordenador adjunto do Observatório do Dendê. cleisongeo@gmail.com / http://orcid.org/0000-0001-6190-0705

Recebido para avaliação em 16/07/2020; Aceito para publicação em 10/11/2020.

\section{RESUMO}

No texto sustenta-se que a dendeicultura atua como agrohidronegócio na Amazônia paraense. Enquanto produção do espaço do capital, ela usufrui de recursos hídricos a partir da apropriação da terra, confundindo direito de propriedade com direito à propriedade. Por agrohidronegócio compreende-se uma categoria analítica das tensões, disputas e conflitos territoriais decorrentes da ação do capital para usar e se apropriar dos corpos hídricos no espaço. Entende-se por dendeicultura as determinações espaciais que possibilitam o cultivo do dendezeiro nesta fração da Amazônia e por meio destas reorganizar a paisagem, a configuração espacial e a dinâmica social dos lugares sob sua influência. Mostra-se que a necessidade imperativa de água explica a distribuição dos dendezais nas sub-bacias hidrográficas da microrregião de Tomé-açu, ocasionando impactos ambientais. Por isso cria-se uma representação espacial que oculta tais impactos, nem mesmo a captação de água. Na literatura a água não aparece para esse agrohidronegócio como insumo na composição dos custos da produção de óleos de dendê e nenhuma empresa é cobrada pelo direito de uso. O direito de outorga para captar água parece suficiente para dizer que estão cumpridas as determinações da política nacional de recursos hídricos. Está-se diante de prática que produz uma

1 Artigo fruto do projeto de pesquisa: Dendeicultura e impactos socioambientais no meio rural da microrregião de Tomé-açu, na Amazônia paraense. 
representação de espaço onde esse vetor econômico silencia suas responsabilidades, impactos e riscos ambientais e se apresenta como recuperador de áreas degradadas econômica e ambientalmente, gerador de empregos, renda e inclusão social.

Palavras-chave: Dendê; Rural; Outorgas; Água; Apropriação.

\begin{abstract}
It is argued that oil palm cultivation acts as an hydroagricultural business in the Pará's Amazon. As production of the capital space, it takes advantage of water resources based on the appropriation of land, confusing the right of property with the right to property. Hydroagricultural business is an analytical category of tensions, disputes and territorial conflicts resulting from the action of capital to use and appropriate water bodies in space. Oil palm cultivation is understood as the spatial determinations that make it possible to cultivate oil palm in this part of the Amazon and, through these, reorganize the landscape, the spatial configuration and the social dynamics of the places under its influence. It is shown that the imperative need for water explains the distribution of oil palm in the hydrographic sub-basins of the micro-region of Tomé-açu causing environmental impacts. That is why a spatial representation is created that hides such impacts, not even the water catchment. In the literature, water does not appear to this hydroagricultural business as an input in the composition of the costs of producing palm oil and no company pays for the right to use it. The granting right to collect water seems sufficient to say that the determinations of the national water resources policy are being fulfilled. It is a practice that produces a representation of space where this economic vector silences its responsibilities, impacts and environmental risks and presents itself as a recuperated of degraded areas economically and environmentally, generating jobs and social inclusion.
\end{abstract}

Keywords: Oil Palm; Rural; Grants; Water; Appropriation.

\title{
RESUMEN
}

El texto argumenta que la dendeicultura actúa como agrohidronegócio en la Amazonía paraense. Mientras produce el espacio de lo capital, disfruta de los recursos hídricos de la apropiación de la tierra, confundiendo los derechos de propiedad con el derecho a la propiedad. Agrohidonegocío es una categoría analítica de tensiones, disputas y conflictos territoriales derivados de la acción del capital para utilizar y cuerpos de agua apropiados en el espacio. La dendeicultura se entiende como las determinaciones espaciales que permiten el cultivo de palma aceitera en esta fracción de la Amazonía y a través de estos reorganizar el paisaje, la configuración espacial y la dinámica social de los lugares bajo su influencia. Se demuestra que la necesidad imperiosa de agua explica la distribución de palmas de aceite en las subcuencas hidrográficas de la microrregión de Tomé-açu, causando impactos ambientales. Por lo tanto, se crea una representación espacial que oculta tales impactos, ni siquiera la captura de agua. En la literatura el agua no aparece para este agrohidronegócio como insumo en la composición de los costos de la producción de aceites de palma y no se cobra a ninguna empresa por el derecho de uso. El derecho de concesión a capturar el agua parece suficiente para decir que se cumplen las determinaciones de la política nacional de recursos hídricos. Se enfrenta a una práctica que produce una representación del espacio donde este vector económico silencia sus responsabilidades, impactos y riesgos ambientales y se presenta como una recuperación de áreas económica y ambientalmente degradadas, generando empleos, ingresos e inclusión social.

Palabras clave: Palma Aceitera; Rural; Subvenciones; Agua; Apropiación.

\section{INTRODUÇÃO}

Enfocamos os usos e abusos dos recursos hídricos pela dendeicultura, concebendoa tal como exemplo de agrohidronegócio. O termo agrohidronegócio integra pesquisas cujo 
objetivo é compreender de forma articulada os usos da terra, trabalho e recursos hídricos (THOMAZ JUNIOR, 2017). Trata-se de uma categoria analítica das tensões, disputas e conflitos territoriais decorrentes da ação do capital para usar e se apropriar dos corpos hídricos no espaço; auxilia na compreensão da produção do espaço para o capital, posto que tem como fato que as cadeias produtivas do agronegócio dependem, além da terra e trabalho, da disponibilidade abundante de água. Está-se diante da apropriação da terra, do trabalho e da água. Entende-se por dendeicultura as determinações espaciais que possibilitam o cultivo do dendezeiro nesta fração da Amazônia e por meio destas a reorganização a paisagem, a configuração espacial e a dinâmica social dos lugares sob sua influência.

A dendeicultura utiliza-se da água captada dentro ou no entorno de áreas de dendezais para produção e beneficiamento do fruto fresco colhido. De modo que "o sucesso do agronegócio não pode ser atribuído somente à sua fixação à territorialização e/ou monopolização das terras, mas também ao acesso e controle da água, assim como às demais etapas da cadeia produtiva, comercialização etc.” (THOMAZ JUNIOR, 2012, p. 11). Interpretada como agrohidronegócio, pode-se entender a produção do espaço rural pela dendeicultura tendo como núcleo da reflexão o uso da água por meio da propriedade da terra.

O objetivo deste artigo é mostrar que a dendeicultura exemplifica a ação do agrohidronegócio no espaço rural da Amazônia paraense. Argumenta-se que na Amazônia paraense a dendeicultura usufrui de recursos hídricos a partir da apropriação da terra, confundindo direito de propriedade com direito à propriedade, pois necessita dispor de rede hídrica, nascentes, águas subterrâneas e outorgas para o beneficiamento do fruto fresco colhido, transformando-o, por exemplo, em óleo.

\section{MATERIAIS E MÉTODOS}

Inicialmente mapeou-se a distribuição do cultivo do dendezeiro nas sub-bacias da microrregião de Tomé-açu entre os anos de 1988 a 2018. Para tanto, classificou-se imagens de satélites Landsat TM/5 e OLI/8, adquiridas no repositório público do United States Geological Survey (USGS), conhecido como EarthExplorer, com base no menor número de nuvens por cena. Para a identificação das áreas empregou-se elementos de interpretação visual de imagens elaboradas a partir da forma, que está relacionada à geometria do objeto; do tamanho, que varia conforme a resolução espacial da imagem; da tonalidade, relacionada 
|João Santos Nahum | Leonardo de Sousa Santos | Cleison Bastos dos Santos |

à quantidade de energia refletida por um objeto; e da textura, que pode ser lisa ou rugosa (VASCONCELOS, 2013).

Utilizaram-se técnicas de processamento digital, baseadas nas características radiométricas/espectrais dos pixels por meio do software PCI Geomátics. Para classificação automática do $\mathrm{CD} / 2018$ da imagem foi realizada pelo algoritmo "Máximaverossimilhança" (MaxVer) do ENVI 4.8®, com uma matriz de confusão que gerou exatidão global de 90,3\% e índice de Kappa de 0,85, sendo satisfatório pelas amostras utilizadas e ao resultado que se pretende alcançar.

Mapeadas as áreas de cultivo, coletaram-se dados para caracterizar a distribuição dos dendezais e dos direitos de outorga pelas sub-bacias da microrregião de Tomé-açu. Igualmente, a partir das informações da Secretaria de Estado de Meio Ambiente e Sustentabilidade do Pará (SEMAS) foram identificadas a quantidade de outorgas, sua distribuição e o volume aproximado de captação de água. Realizou-se trabalho de campo para verificar os impactos e os riscos ambientais, especialmente nos corpos hídricos. Contrastou-se o mapeamento, os dados de outorgas e as informações de campo com o silenciamento sobre o tema reinante na literatura que privilegia o cultivo do dendezeiro em detrimento da cadeia produtiva do dendê e da produção de óleos de palma. Tal silenciamento ressalta a estratégia de confundir direito à propriedade com direito de propriedade. O corolário disso é a ausência do comitê de bacias, o cultivo de dendezeiro em área de nascente e assoreamento de igarapés.

A situação empírica da reflexão abrange os dendezais da microrregião de Tomé-açu, composta pelos municípios do Moju, Acará, Tailândia, Tomé-açu e Concórdia do Pará. O espaço rural destes municípios é marcado por densos mosaicos de dendezais plantados no decorrer das décadas de 1980 pela REASA (Reflorestadora da Amazônia S/A) - atualmente Marborges-, em 1990 pela Agropalma, e no século XXI pela Biopalma, Petrobras/Biocombustível, Belém Bioenergia Brasil (BBB), Archer Daniels Midland Company (ADM), Guafeng Group. Os dados da Embrapa ${ }^{2}$ mostram que a microrregião de Tomé-açu tinha em 1990 20,04 mil/ha, aumentando para 22,84 ml/ha em 2000, 38,28 mil/ha em 2010 e 75,27 mil/ha em 2018. Os dendezais distribuídos pelas sub-bacias da microrregião e cujos recursos hídricos são fundamentais para a dendeicultura.

\section{RESULTADOS E DISCUSSÃO}

\footnotetext{
${ }^{2}$ Fonte:

https://bi.sede.embrapa.br/BOE/OpenDocument/1904021325/OpenDocument/opendoc/openDocument faces? logonSuccessful=true\&shareId=2. Acesso em: 19 jun.2020.
} 
Segundo Teixeira et al. (2018, p. 31), a bacia hidrográfica "é a figura central dos estudos hidrológicos, conforme a Lei 9.433, como a unidade básica de planejamento de recursos hídricos, expressão usada para referir à água que está sendo usada ou em vista de uso". As bacias hidrográficas são responsáveis pela produção de água em uma determinada região. Estando assentada sobre um conjunto de bacias a dendeicultura é consumidora intensiva de recursos hídricos para o cultivo do dendezeiro, a cadeia produtiva de dendê e derivados.

Segundo United States Department of Agriculture, em 2019, os dendezais brasileiros abrangeram $175 \mathrm{mil} /$ ha e produziram 525.000 toneladas de óleo de palma ${ }^{3}$. Neste ano, aceitando-se que se "utiliza a média de $6,2 \mathrm{mil} / \mathrm{m}^{3}$ de água para produzir uma tonelada de óleo de dendê" (ALVES et al., 2013, p. 241), foram usados $3.255 \mathrm{bi} / \mathrm{m}^{3}$ de água para gerar a referida produção. Observando-se, segundo Hoekstra e Hung (2002), que são necessários $12.780 \mathrm{~m}^{3}$ no cultivo de 1 hectare de dendezeiro, tem-se um consumo aproximado de 2,24 bi/ $\mathrm{m}^{3}$ de água no cultivo do dendezeiro. Para Venturieri et al. (2017, p. 15), "uma indústria com 3.000 ha de dendezal demandaria $166.666 \mathrm{~m}^{3}$ de água.dia-1 e uma agroindústria com 10.000 ha de área de plantio demandaria $555.555 \mathrm{~m}^{3}$ de água.dia- ${ }^{1}$ ”. Vêse que, por meio do direito de outorga de uso dos corpos hídricos concedido pelo Estado, as empresas transformam água em mercadoria exportada nos produtos derivados dos frutos frescos colhidos do dendezeiro, por exemplo, o óleo de dendê e de palmiste.

Integrando o agrohidronegócio, os dendezais se distribuem nas sub-bacias hidrográficas da microrregião de Tomé-açu. A Tabela 1 expõe a distribuição do cultivo pelas sub-bacias nos municípios de Acará, Concórdia do Pará, Moju, Tailândia e Tomé-açu.

Tabela 1 - Distribuição do cultivo do dendezeiro por sub-bacias hidrográficas na microrregião de Tomé-açu Sub-bacias (PA) em 2018

\begin{tabular}{|c|c|c|c|c|c|c|}
\hline & Acará & $\begin{array}{c}\text { Concórdia do } \\
\text { Pará }\end{array}$ & Moju & Tailândia & Tomé-Açu & $\begin{array}{l}\text { Área cultivada } \\
\text { (sub-bacia/ha) }\end{array}$ \\
\hline Rio Bujaru & & 6.114 & & & 185 & 6.299 \\
\hline Rio Ubá & & & 16.924 & & & 16.924 \\
\hline Rio Mamorana & & & 1.0970 & & & 1.097 \\
\hline Rio Moju & & & 24.505 & 86 & & 24.591 \\
\hline Rio Acará & 18.050 & 178 & 10.243 & 59.869 & 59.750 & $1.480,90$ \\
\hline $\begin{array}{l}\text { Área cultivada } \\
\text { (município/ ha) }\end{array}$ & 18.050 & 6.292 & 52.769 & 59.955 & 59.935 & \\
\hline
\end{tabular}

Fonte: Dados geoprocessados pelos autores.

\footnotetext{
${ }^{3}$ Fonte: https://www.indexmundi.com/agriculture/?country=br\&commodity=palm-oil\&graph=production.
} Acesso em: 29 maio 2020. 
|João Santos Nahum | Leonardo de Sousa Santos | Cleison Bastos dos Santos |

A Tabela 1 realça que os maiores dendezais estão no município de Tailândia, seguido de Tomé-açu, Moju, Acará e Concórdia do Pará. A maior área de cultivo de dendezeiro está na sub-bacia do rio Acará, que abrange todos os municípios da microrregião de Tomé-açu. Dentro desta bacia temos cultivo nos municípios de Acará, Concórdia do Pará, Moju, Tailândia e Tomé-açu.

Intenso consumidor, o agrohidronegócio do dendê requer captação de água, como indicam as tabelas 2 e 3 .

Tabela 2 - Outorga de água dentro dos dendezais na microrregião de Tomé-açu-2017

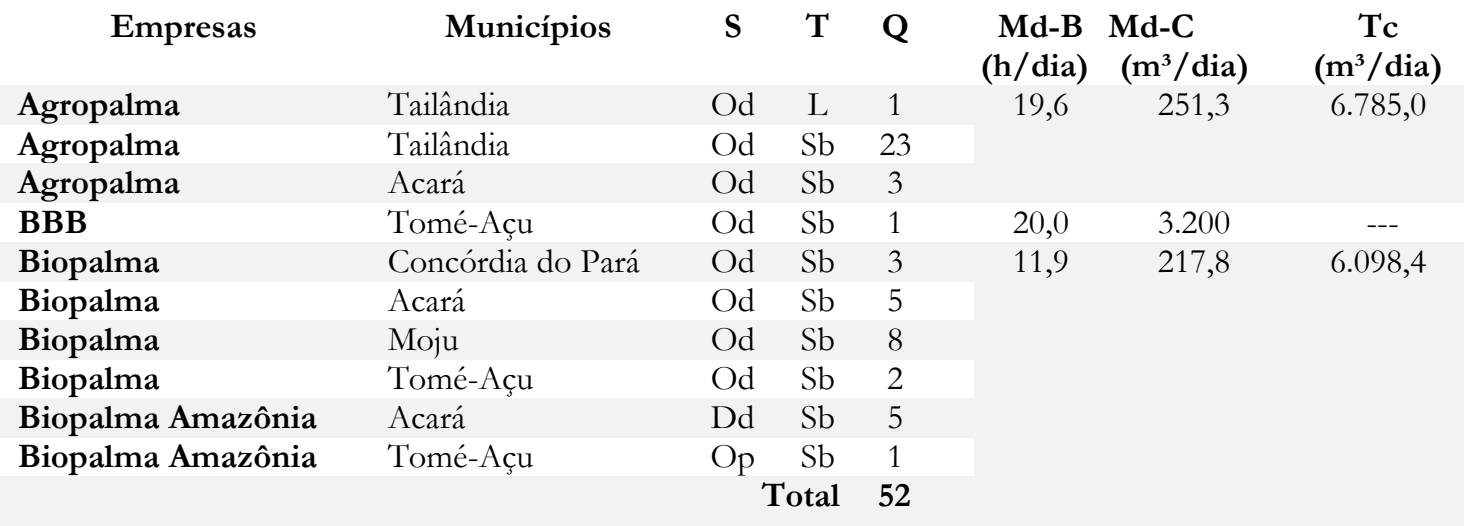

Nota: S:Situações; T:Tipo; Q:Quantidade; Md-B: Média de bombeamento por outorga; Md-C: Média de captação por outorga; Tc:Taxa de captação; Od:Outorga de direito; Dd:Declaração de dispensa; Op: Outorga prévia; L:Lançamento; Sb: Subterrânea; Sp: Superficial. Fonte dos dados: Secretaria Estadual do Meio Ambiente. Organizada pelos autores.

Tabela 3 - Outorga de água fora dos dendezais na microrregião de Tomé-açu-2017

\begin{tabular}{|c|c|c|c|c|c|c|c|}
\hline Empresas & Municípios & $\mathbf{S}$ & $\mathbf{T}$ & Q & $\begin{array}{l}\text { Md-B } \\
\text { (h/dia) }\end{array}$ & $\begin{array}{c}\text { Md-C } \\
\left(\mathrm{m}^{3} / \mathrm{dia}\right)\end{array}$ & $\begin{array}{c}\text { Tc } \\
\left(\mathrm{m}^{3} / \mathrm{dia}\right)\end{array}$ \\
\hline Agropalma & Acará & $\mathrm{Od}$ & $\mathrm{Sb}$ & 1 & \multirow[t]{2}{*}{6,8} & \multirow[t]{2}{*}{775,7} & \multirow[t]{2}{*}{6205,4} \\
\hline Agropalma & Tailândia & Od & $\mathrm{Sb}$ & 7 & & & \\
\hline & & & & & \multirow[t]{3}{*}{---} & \multirow[t]{3}{*}{2400,0} & \multirow[t]{3}{*}{---} \\
\hline BBB & Tailândia & Od & Sp & 1 & & & \\
\hline BBB & Tailândia & $\mathrm{Od}$ & $\mathrm{Sb}$ & 4 & & & \\
\hline Biopalma Amazônia & Acará & Od & $\mathrm{Sb}$ & 4 & \multirow[t]{7}{*}{8,6} & \multirow[t]{7}{*}{21,5} & \multirow[t]{7}{*}{301,0} \\
\hline Biopalma Amazônia & Acará & Od & $\mathrm{Sb}$ & 2 & & & \\
\hline Biopalma Amazônia & Moju & Od & $\mathrm{Sb}$ & 1 & & & \\
\hline Biopalma Amazônia & Tomé-Açu & Od & $\mathrm{Sb}$ & 1 & & & \\
\hline $\begin{array}{l}\text { Biopalma Amazônia / } \\
\text { Reflorestamento }\end{array}$ & Tomé-Açu & Dd & $\mathrm{Sb}$ & 2 & & & \\
\hline $\begin{array}{l}\text { Biopalma Amazônia / } \\
\text { Reflorestamento }\end{array}$ & Acará & Od & $\mathrm{Sb}$ & 2 & & & \\
\hline $\begin{array}{l}\text { Biopalma Amazônia / } \\
\text { Reflorestamento }\end{array}$ & Moju & Od & $\mathrm{Sb}$ & 1 & & & \\
\hline Dendê Tauá S/A & $\begin{array}{l}\text { Concórdia do } \\
\text { Pará }\end{array}$ & Od & $\mathrm{Sb}$ & 1 & 2 & 40 & --- \\
\hline \multirow[t]{2}{*}{ Marborges } & Moju & $\mathrm{Od}$ & $\mathrm{Sb}$ & 4 & \multirow[t]{2}{*}{14,0} & \multirow[t]{2}{*}{108,7} & \multirow[t]{2}{*}{434,6} \\
\hline & & & otal & 31 & & & \\
\hline
\end{tabular}

Nota: S:Situações; T:Tipo; Q:Quantidade; Md-B: Média de bombeamento por outorga; Md-C: Média de captação por outorga; Tc:'Taxa de captação; Od:Outorga de direito; Dd:Declaração de dispensa; Op: Outorga prévia; L:Lançamento; Sb: Subterrânea; Sp: Superficial. Fonte dos dados: Secretaria Estadual do Meio Ambiente. Organizada pelos autores. 
As tabelas 2 e 3 mostram 83 outorgas na microrregião de Tomé-açu, desta 52 pontos estão no interior de dendezais e 31 no exterior. A Agropalma S/A tem 35 pontos outorgados, destes 27 estão dentro dos dendezais; a Biopalma 37 pontos, do quais 24 estão em dendezais; a BBB 6 pontos, sendo 1 no dendezal; a Marborges em 4 pontos fora do dendezal; e a Dendê Taua S/A tem 1 ponto fora do dendezal. Ainda quanto à captação nos talhões, as referidas tabelas indicam que a maior concentração de pontos de outorga está no meio rural do município de Tailândia (36 pontos), seguido pelo Acará (22 pontos), Moju (14 pontos), Tomé-açu (7 pontos) e Concórdia do Pará (4 pontos).

As tabelas 2 e 3 assinalam a maior captação feita pela Agropalma, seguida da Biopalma. A Secretaria de Estado de Meio Ambiente e Sustentabilidade do Pará (SEMAS) não disponibilizou dados da Belém Bioenergia Brasil (BBB). A empresa Belém Bioenergia Brasil (BBB) tem a maior média de bombeamento diário por outorga dentro dos dendezais, seguida pela Agropalma e Biopalma. Quanto à outorga fora dos dendezais, a empresa Marborges tem a maior média de bombeamento diário, seguida pela Biopalma, Agropalma e Dendê Taua S/A.

No entanto, esse agrohidronegócio cria uma representação espacial sem impacto ao meio ambiente, nem mesmo a captação de água. A literatura sobre a dendeicultura limita-se ao cultivo do dendezeiro e enfoca a pluviosidade e o balanço hídrico favorável, senão vejamos. Silva et al. (2003, p. 20) menciona que "o dendezeiro é planta muito exigente em água no solo e pouco tolerante às deficiências hídricas (...), considerando-se que locais com deficiências hídricas abaixo de $100 \mathrm{~mm}$ são ao mais indicados para o cultivo do dendezeiro".

Kaltner et al. (2004, p. 30-31) não incluem a água entre os principais insumos na cadeia agroindustrial de óleo de palma que, para eles, são as sementes germinadas, adubos, defensivos, óleo diesel, energia elétrica. Mesmo entendimento é o de Furlan Júnior et al. (2006, p. 83-84), para os quais os principais insumos na agroindústria de óleo de palma são sementes germinadas, defensivos, adubos, óleo diesel, energia elétrica, tamanho e estrutura das fazendas. E nas premissas de cálculo do balanço energético de biodiesel a partir do dendezeiro estão, por exemplo, incluídas mão de obra, gastos com diesel, adubação, calcário, boro, quantidade de sementes, herbicida, inseticida, transporte - exceto a água.

Quando Müller e Alves (1997, p. 19) tratam das "exigências ambientais para se plantar o dendê", o uso dos recursos hídricos está ausente, ainda que mencionem o balanço hídrico, o resumem à quantidade e intensidade de chuvas. O uso de água não aparece quando Müller e Alves (1997, p. 26-27) discorrem sobre o pré-viveiro e o viveiro, apesar de mencionarem que: 
As culturas perenes arbóreas são geralmente consideradas como as mais indicadas para as regiões tropicais úmidas, como a Amazônia, devido às árvores possuírem alguns atributos que as tornam apropriadas para as condições de alta precipitação pluviométrica e solos relativamente pobres (MÜLLER; ALVES, 1997, p. 37).

Barcelos et al. (1987, p. 10-11) não incluem a existência de corpos hídricos entre as exigências ecológicas (temperatura, precipitação, insolação, solos) para o cultivo do dendezeiro. O que é contraditório, pois reconhecem que "o viveiro deve ser localizado próximo a uma fonte d'água para alimentar as mudas nele contidas, de acordo com suas necessidades, que são de aproximadamente $80 \mathrm{~m}^{3} /$ dia/ha de viveiro, durante a estação seca” (BARCELOS et al., 1987, p. 14). Para Barcelos et al. (1987, p. 11), é a precipitação “o mais importante elemento de clima para o crescimento e a produção do dendezeiro, em razão do dendê ser muito exigente em água, não tolerando regiões secas”. Mesmo assim, quando se referem à irrigação, Barcelos et al. (1987, p. 17) reconhecem que "a reserva de água é suficiente, para simplificar a organização adota-se um ritmo de três turnos de rega/semana. Após uma irrigação o balanço hídrico deve ser igual à reserva de água facilmente utilizável".

A importância da água não passou despercebida para Veiga, Sinimbu e Ramos (2001) no trabalho sobre irrigação em dendezeiro na região do Acará, para os quais:

A disponibilidade de água tem grande influência no tamanho das folhas e nas variações estacionais do surgimento de novas folhas, uma vez que a fase de alongamento rápido das floras exige grande quantidade de água. Essas variações têm reflexos também na produção, já que o ritmo de formação de novas inflorescências acompanha o de emissão de novas folhas (VEIGA; SINIMBU; RAMOS, 2001, p. 12).

Mas quando Veiga, Sinimbu e Ramos (2001) tratam das características necessárias para o cultivo do dendezeiro, apontam localização, clima, solo, vegetação de cobertura, porém não fazem referência ao uso dos recursos hídricos. Igualmente, até 16 de julho de 2020, quando se pesquisou no site das empresas Marborges agroindústria, Belém Bioenergia Brasil (BBB), Archer Daniels Midland Company (ADM), não se encontrou nem o relatório de sustentabilidade nem referência a uso de recursos hídricos no processo de produção de óleos do dendezeiro, inclusive, a empresa Dendê Tauá S/A sequer possui website.

Entretanto, para o cultivo do dendezeiro, tão importante quanto bom índice pluviométrico e balanço hídrico é a água de poços e a captada das sub-bacias sobre as quais os dendezais da Amazônia paraense estão assentados e que fornecem água para o 
processamento na agroindústria do fruto fresco colhido. Fato reconhecido nos relatórios de sustentabilidade da Agropalma:

\begin{abstract}
Usamos água de rio e de poço no processamento dos frutos - pouco menos de uma tonelada métrica de água por tonelada métrica de CFF processados em nossas usinas - e observamos um aumento nos últimos anos. Isto porque reduzimos nossa utilização de água reciclada depois de descobrir que poderia ter um efeito sobre o nível de 3-MPCD e outros contaminantes que potencialmente podem afetar a qualidade do produto. Além disso, devido à produção menor de CFF e a inauguração da nova usina, nossas usinas não estão operando a plena capacidade, porém como aproximadamente o mesmo volume de água é necessário para operar as usinas, a relação água/CFF aumentou (AGROPALMA, 2017, p. 24).
\end{abstract}

O silenciamento desse agrohidronegócio em relação ao uso dos recursos na produção da cadeia produtiva expressa o que Chauí (1981) designa por discurso competente feito de lacunas e ressaltando uma dimensão do processo, qual seja, a geração de emprego, renda, inclusão social, recuperação de áreas degradadas, dentre outros componentes discursivos promotores do desenvolvimento territorial rural. A literatura examinada sobre o cultivo do dendezeiro não relaciona essa prática espacial à cadeia produtiva dos óleos de dendê nem ao crescente mercado consumidor mundial (NAHUM; SANTOS, 2018a; NAHUM; SANTOS, 2018b). Assim reduzida, o leitor deduzirá que são exportados frutos frescos colhidos. Ora, o que se exporta é óleo de palma e para obtê-lo é necessário uso intensivo de recursos hídricos.

Nas tabelas 2 e 3 demostrou-se a distribuição dos dendezais nas bacias da microrregião de Tomé-açu. As empresas conseguiram direito de outorga para captação e uso de águas dos corpos hídricos dentro e fora da área de cultivo. No relatório da Biopalma, ao mencionar o direito de outorga, lê-se que:

\footnotetext{
A empresa apoia as iniciativas tecnológicas e funcionais para redução do consumo e tratamento adequado das águas provenientes de suas captações. Grande parte da água captada em rios e poços artesianos, devidamente outorgados, destina-se ao processo industrial, uma vez que a cultura da palma não exige irrigação (BIOPALMA, 2016, p. 31, grifos nossos).
}

O devidamente outorgado tem a função discursiva de ressaltar que a empresa está autorizada a captar água, como se apenas este ato fosse suficiente para dizer que estão cumpridas as determinações da Política Nacional de Recursos Hídricos (BRASIL, 1997). Porém, a água captada do subsolo e das sub-bacias é um insumo imprescindível ao processo produtivo. Mas tanto a ação das empresas quanto a literatura revisada sugerem que os corpos hídricos por estarem na propriedade constituem bem do proprietário, cujo uso requer tão somente autorização. Neste artifício, o agrohidronegócio acredita que a 
|João Santos Nahum | Leonardo de Sousa Santos | Cleison Bastos dos Santos |

abundância da água justifica seu uso sem qualquer pagamento ou compensação para a sociedade onde a cadeia produtiva está situada. Não sendo contabilizado nem classificado como insumo no processo produtivo, funciona tal como espécie de incentivo ambiental cujos usos são franqueados desde que se tenha licença.

Para o agrohidronegócio, a água não aparece como insumo na composição dos custos da produção de óleos de dendê, posto que não se exige pagamento de nenhuma empresa pelo uso da água decorrente do direito de outorga, pois ainda são raros os comitês de bacias. Somente no dia 04/09/2019,

O Estado anunciou, nesta quarta-feira (4), a criação do Comitê da Bacia Hidrográfica do Rio Marapanim (CBHRM), situada na Costa Atlântica-Nordeste do Pará. A informação foi divulgada pelo titular da Secretaria de Estado de Meio Ambiente e Sustentabilidade (Semas), Mauro O'de Almeida, durante o evento a mesa redonda "Desafios da agenda ambiental e das cidades na Amazônia para a implementação do Acordo de Paris: o caso do Pará". O evento, que contou com a presença do governador Helder Barbalho, foi realizado no salão principal do Palácio dos Despachos, em Belém (FRIAS, 2019, s.p.).

Anuncia-se a criação do Comitê da Bacia Hidrográfica do Rio Marapanim (CBHRM) aproximadamente vinte e dois anos após a Lei $\mathrm{N}^{\circ}$ 9.433, de 08 de janeiro de 1997 instituir a Política Nacional de Recursos Hídricos e criar o Sistema Nacional de Gerenciamento de Recursos Hídricos (BRASIL, 1997). Em se tratando do Estado do Pará, a Lei 6.381 que estabelece a Política Estadual de Recursos Hídricos é de 25 de julho de 2001(ALEPA, 2001) e o Decreto n 276 que regulamenta o Conselho Estadual de Recursos Hídricos, data de 02 de dezembro de 2011(ALEPA, 2011); é de 28 de fevereiro de 2013 o decreto que designa membros para o Conselho Estadual de Recursos Hídricos e dá outras providências (GOVERNO DO ESTADO DO PARÁ, 2013); de 23 de novembro de 2018, a Resolução no 16 , que estabelece diretrizes para a formação e funcionamento dos Comitês de Bacias Hidrográficas, no âmbito do Estado do Pará (GOVERNO DO ESTADO DO PARÁ, 2018a). Data de 05 de dezembro de 2018 a Resolução no 17, que dispõe sobre o Regimento Interno do Conselho Estadual de Recursos Hídricos do Estado do Pará (GOVERNO DO ESTADO DO PARÁ, 2018b); é de 27 de dezembro de 2018 a Resolução no 18 , dispõe sobre as diretrizes de elaboração do Plano Estadual de Capacitação em Recursos Hídricos (GOVERNO DO ESTADO DO PARÁ, 2018c).

O hiato entre o estabelecimento dessa Lei Federal e sua tradução na esfera de Leis Estadual, indica que o agrohidronegócio, em sua aparente modernidade, ratifica a natureza rentista do capitalismo brasileiro, pois no seu verniz moderno brilha o poder do atraso de que nos alerta Martins (1999). Essa é a prática recorrente no bloco no poder do estado brasileiro em sua incansável metamorfose para parecer moderno por meio de atos que 
|João Santos Nahum | Leonardo de Sousa Santos | Cleison Bastos dos Santos |

remodelam sua face mais tradicional e conservadora. O bloco de poder hegemônico no estado brasileiro procura frequentemente se manter atualizado no que se refere ao ordenamento jurídico hegemônico no grupo de países do G7 (Alemanha, Canadá, Estados Unidos, França, Itália, Japão e Reino Unido). Assim, em se tratando de uso dos recursos hídricos, tal como ressaltam Braga e Argollo Ferrão (2015), a experiência francesa tem se revelado como importante referência na institucionalização de novas práticas gestoras. "No Brasil, esta experiência é a base não apenas da constituição dos novos aparatos gestores estaduais, mas também da própria formulação da Política Nacional de Recursos Hídricos” (BRAGA; ARGOLLO FERRÃO, 2015, p. 20).

No capítulo III da Lei no 9.433, de 8 de janeiro de 1997 que trata do comitê de bacias lê-se que este é composto por representantes da União, dos Estados e do Distrito Federal cujos territórios se situem, ainda que parcialmente, em suas respectivas áreas de atuação; dos Municípios situados, no todo ou em parte, em sua área de atuação; dos usuários das águas de sua área de atuação; das entidades civis de recursos hídricos com atuação comprovada na bacia (BRASIL, 1997). Dentre as atribuições do comitê compete:

\footnotetext{
I - Promover o debate das questões relacionadas a recursos hídricos e articular a atuação das entidades intervenientes;

II - arbitrar, em primeira instância administrativa, os conflitos relacionados aos recursos hídricos;

III - aprovar o Plano de Recursos Hídricos da bacia;

IV - acompanhar a execução do Plano de Recursos Hídricos da bacia e sugerir as providências necessárias ao cumprimento de suas metas;

$\mathrm{V}$ - propor ao Conselho Nacional e aos Conselhos Estaduais de Recursos Hídricos as acumulações, derivações, captações e lançamentos de pouca expressão, para efeito de isenção da obrigatoriedade de outorga de direitos de uso de recursos hídricos, de acordo com os domínios destes;

VI - estabelecer os mecanismos de cobrança pelo uso de recursos hídricos e sugerir os valores a serem cobrados;

VII - (VETADO)

VIII - (VETADO)

IX - estabelecer critérios e promover o rateio de custo das obras de uso múltiplo, de interesse comum ou coletivo (BRASIL, 1997).
}

As bacias hidrográficas tornaram-se base espacial para a política nacional de recursos hídricos (BRASIL, 1997), e, se fossem consideradas as atribuições do comitê de bacias, tal política deveria moldar-se em fundamentos participativos, democráticos, transparentes e federativos. O comitê deveria assumir conotação territorial, isto é, envolver as pessoas diretamente afetadas pelo uso dos recursos. Aqui se manifesta o poder do atraso do agrohidronegócio, pois na Amazônia paraense o comitê de bacia parece não sair do plano de intenções de pesquisadores engajados em associações comunitárias dos lugares impactados pela apropriação e uso dos recursos hídricos por empresas que se estabelecem amparadas no discurso de desenvolvimento territorial rural. Ainda que para isso tais 
empresas tenham que se apropriar intensivamente e predatoriamente do bem supremo, que é a água.

Em se tratando da dendeicultura, as empresas exercem influência sobre inúmeras comunidades rurais e cujos moradores têm nas atividades de cultivo e processamento do fruto fresco colhido uma das principais, senão a principal fonte de renda (NAHUM, BASTOS, 2014). Por exemplo, 20\% dos frutos processados pela AGROPALMA "são oriundos de pequenos e médios produtores da comunidade. Também trabalhamos junto a esses produtores para garantir que observem os mesmos padrões elevados que exigimos em nossas próprias operações” (AGROPALMA, 2017, p. 28). Além disso, foi por meio da dendeicultura que o aluguel de habitações rurais se generaliza e impulsiona o comércio local, estradas e ramais são mantidos trafegáveis, portos, pontes, eletrificação rural, posto de saúde, de polícia, transporte rural regular, escola rural, dentre outras tantas ações de reconfiguração no arranjo espacial local (CARVALHO; NAHUM, 2019).

O ofensivo agrohidronegócio da dendeicultura integra um cenário político no qual o nível de organização sindical é mínimo e as demandas da vida máximas. Neste cenário, o privilégio da servidão, tal como enfatiza Antunes (2018), motiva o agricultor a se integrar à cadeia produtiva do dendê e a não formar associação de moradores das áreas de abrangência da dendeicultura para organizar um comitê de bacia capaz de avaliar o impacto dessa atividade nos corpos hídricos, bem como estabelecer um valor a ser pago pela empresa pelo direito de uso desse bem.

A prática espacial das empresas produz uma representação de espaço onde esse vetor econômico silencia suas responsabilidades, impactos e riscos ambientais e se apresenta como recuperador de áreas degradadas econômica e ambientalmente (BERTONE, 2011). Tal prática já está presente no projeto piloto de cultivo do dendezeiro por meio da agricultura familiar, o assentamento Arauaí, em 2002. Identificou-se, em trabalho de campo, dendezais plantados em área de nascente, conforme a Figura 1, ignorando que as Áreas de Preservação Permanente (APP) dos cursos de água e nascentes devem ser locais cobertos ou não por vegetação nativa, com a função ambiental de preservar o geossistema de recursos hídricos, estabilizar o geossistema geológico e a biodiversidade, o que não ocorre no assentamento Arauaí associado à Agropalma. 
| Usos e abusos dos recursos hídricos pela dendeicultura na Amazônia paraense |

|João Santos Nahum | Leonardo de Sousa Santos | Cleison Bastos dos Santos |

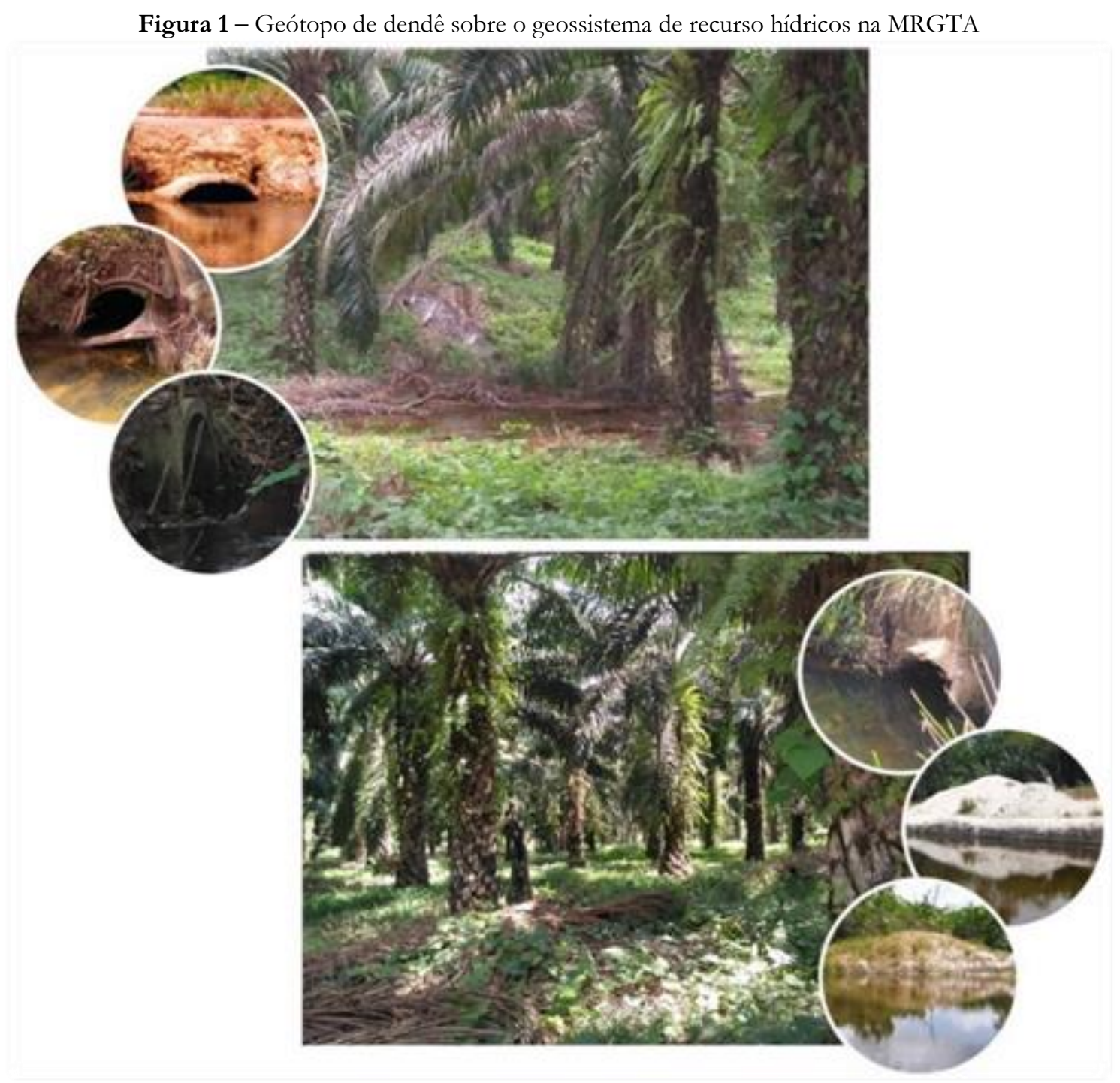

Fotos: Trabalho de campo (2018).

$\mathrm{Na}$ Figura 2, ilustra-se os pontos de nascente processados automaticamente pelo Terrain Analysis Using Digital Elevation Models (TauDEM) por meio de imagens Shuttle Radar Topography Mission (SRTM) e pontos de outorga geocodificados com base nos dados disponibilizados pela Secretaria de Meio Ambiente e Sustentabilidade do Estado do Pará (SEMAS), dentro do Complexo Agropalma e ao lado na área de cultivo do Projetos Arauaí, cultivados entre anos de 2002 a 2006. Observa-se uma região de nascentes identificada com trabalho de campo na área de cultivo dos dendezeiros (seta vermelha), mas que deveria ser local coberto ou não por vegetação nativa. 
|João Santos Nahum | Leonardo de Sousa Santos | Cleison Bastos dos Santos |

Figura 2-Dendezais e nascentes em área da Agropalma na microrregião de Tomé-Açu.

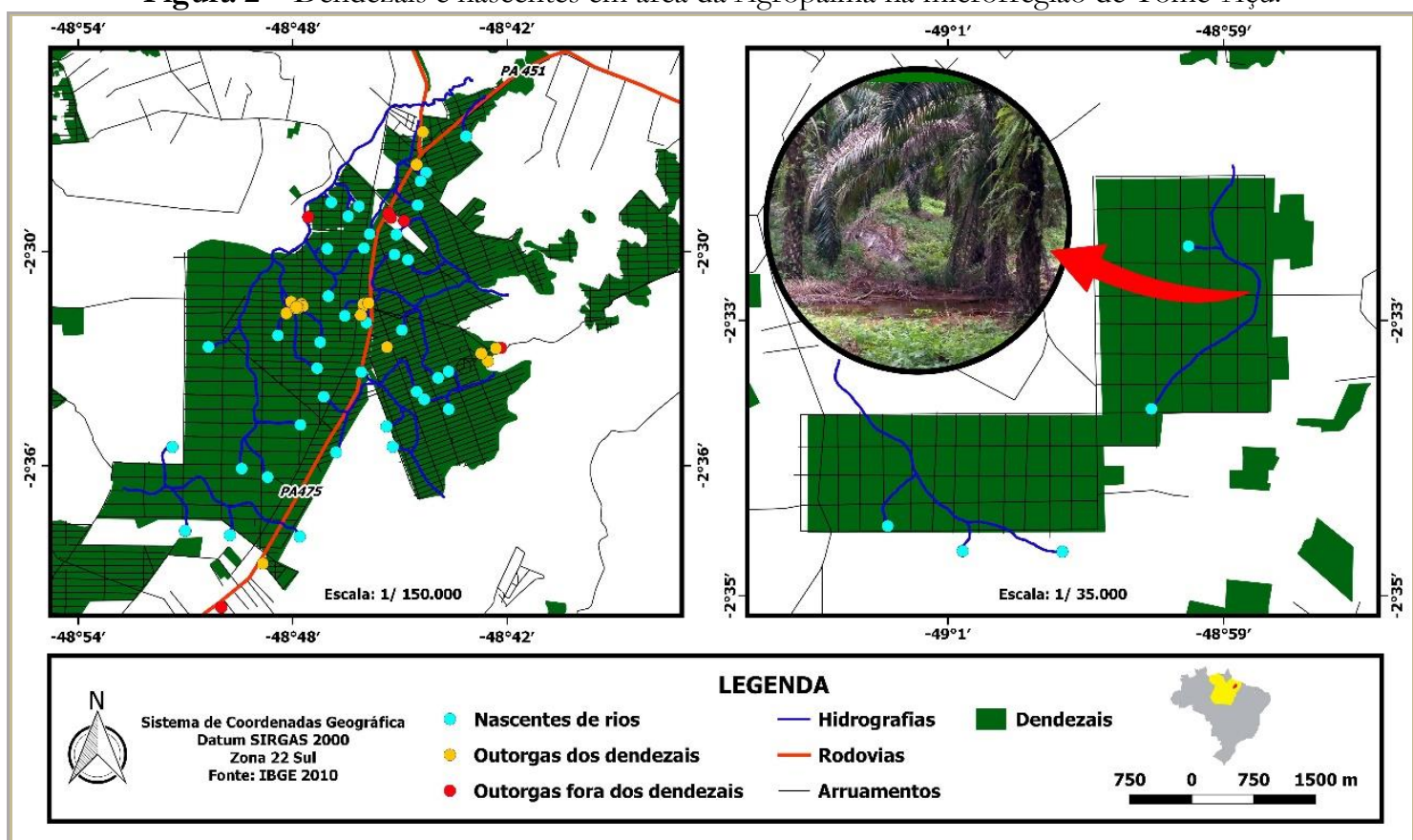

Fonte: Autores, 2019.

Neste cenário tem-se o risco de contaminação de rios e igarapés pela intensidade de herbicidas, fungicidas, bem como de adubo (NAHUM; SANTOS, 2013). Os produtos químicos usados nos plantios para adubação e controle de pragas acabam por ser carregados para os cursos d'água, igarapés e rios que cortam a região. Caso não haja políticas públicas atentas, a expansão dos dendezais exercerá pressão sobre os recursos hídricos, reduzindo-os ao longo do tempo, pelo processo de assoreamento e/ou contaminação por produtos químicos ou pelo derramamento de dendê pelos rios e seus afluentes, provocando impactos ambientais e sociais. Registre-se que em 04 de outubro de 2019 houve "vazamento de dendê e óleo da empresa Agropalma, ocorrido na semana passada, provocou a contaminação de igarapés e do próprio Rio Acará, que corta os municípios do Acará e Tailândia” (REDAÇÃO, 2019). No dia 03 de outubro de 2020, moradores da vila Arraial do Caeté, no município de Ourém, no nordeste do Pará,

interditaram um trecho da PA-124 na manhã deste sábado (3), em protesto pela morte de centena de peixes na localidade. Segundo os manifestantes, um vazamento de um tanque de uma fábrica de dendê teria causado a morte dos animais. Após negociações com a Polícia Militar, segundo os moradores, o problema começou na última sexta (2). Um vazamento de ácido de um tanque da fábrica teria contaminado o rio e matado os peixes. Eles dizem que, por conta da contaminação, não podem utilizar a água do rio para tomar banho, lavar louça e realizar outros afazeres domésticos (G1 PA, 2020). 
Os exemplos acima indicam que a cadeia produtiva do dendê por ter seu arranjo espacial próximo a corpos d'água pode provocar o depósito de insumo no leito dos rios e no lençol freático quando lixiviado nos períodos de chuvas.

\section{CONSIDERAÇÕES FINAIS}

Analisou-se a dendeicultura como agrohidronegócio. Mostrou-se que se trata de um consumidor intensivo de recursos hídricos para o cultivo do dendezeiro, a cadeia produtiva de dendê e derivados. A necessidade imperativa de água explica a distribuição dos dendezais nas sub-bacias hidrográficas da microrregião de Tomé-açu. Tal distribuição causa impactos ambientais, por isso cria-se uma representação espacial que oculta tais impactos, nem mesmo a captação de água. Essa representação está na literatura revisada sobre a dendeicultura que se limita ao cultivo do dendezeiro e, nessa etapa da cadeia produtiva, ressalta a pluviosidade e o balanço hídrico favorável. Nessa literatura a água não aparece para o agrohidronegócio como insumo na composição dos custos da produção de óleos de dendê, pois de nenhuma empresa é exigido o pagamento pelo direito de uso da água. É como se a autorização de outorga para captar água fosse suficiente para dizer que as empresas estão cumprindo às determinações da política nacional de recursos hídricos.

Depreende-se que, na aparente modernidade, o agrohidronegócio ratifica a natureza rentista do capitalismo brasileiro, pois no seu verniz moderno do comitê de bacia brilha o poder do atraso. Isso fica exemplificado na lenta implantação da política nacional de recursos hídricos, sobretudo quando se trata do comitê de bacia. Está-se diante de uma prática espacial das empresas que produz uma representação de espaço onde esse vetor econômico silencia suas responsabilidades, impactos e riscos ambientais e se apresenta como recuperador de áreas degradadas econômica e ambientalmente, gerador de empregos, renda e inclusão social. Tal prática nasce mesmo com o projeto piloto de cultivo do dendezeiro por meio da agricultura familiar, o projeto Arauaí.

Expostas as conclusões centrais, o leitor pode ter notado um tom de denúncia no texto. Longe disso, trata-se de uma reflexão impotente diante da voracidade da dinâmica econômica que tem por meta suprema a mercantilização da água, da terra e da força de trabalho, como se o fundamentalismo do mercado fosse a razão de ser da vida humana.

Dendezais expandiram-se pelas bacias da microrregião de Tomé-açu. Igualmente a cadeia produtiva. Ambos precisam de água, por isso tal distribuição espacial e as outorgas. Mas a literatura examinada praticamente silencia sobre o intenso uso de água na cadeia produtiva de óleos de dendê. Igualmente, a SEMAS silencia acerca do licenciamento 
ambiental do projeto piloto do assentamento Arauaí, ainda que se identifique o descumprimento do código florestal. Também não se encontrou explicação da empresa e da SEMAS para a não formação do comitê de bacias, sabendo-se que a cadeia produtiva do dendê consome intensamente água e causa impactos ambientais.

A presença das empresas e dos empreendimentos parece suficiente para aceitar e justificar o licenciamento ambiental a despeito do descumprimento da política nacional de recursos hídricos e do código florestal. É como se ainda se estivesse na Conferência das Nações Unidas sobre o Meio Ambiente, em Estocolmo, 1972, ouvindo o mesmo discurso onde, "a delegação brasileira, chefiada pelo ministro do Interior, general José Costa Cavalcanti e pelo embaixador Miguel Osório de Almeida, [que] conquistou notoriedade ao defender a subordinação das preocupações ambientais às prerrogativas do crescimento econômico" (ARNT; SCHWARTZMAN, 1992, p. 98). Ao colocar as prerrogativas do crescimento econômico como prioridade do desenvolvimento rural, o agrohidronegócio mostra o descompromisso com os riscos e impactos ambientais, mas, sobretudo, com as gerações futuras.

Dentro desse contexto, sugere-se a constituição de comitê nas sub-bacias hidrográficas da microrregião de Tomé-Açu, enquanto espaço no qual as comunidades na área de abrangência poderão discutir e deliberar sobre a gestão do uso da água e, por conseguinte, do território. O comitê de bacia hidrográfica, sustentado em pesquisas como esta, poderá tomar decisão e auxiliar na elaboração das políticas para gestão das águas das cinco sub-bacias dessa microrregião, especialmente na área de plantio, onde existe risco aos usos múltiplos da água em quantidade e qualidade, conforme assegurados em Lei. Longe de uma perspectiva legalista, apenas sugere-se que Estado e empresas dendeicultoras devam considerar aqueles que têm suas vidas impactadas pela cadeia produtiva do dendê, principalmente no que refere aos usos e abusos dos recursos hídricos.

\section{REFERÊNCIAS}

ALEPA. Lei $\mathbf{n}^{\mathbf{0}} \mathbf{6 . 3 8 1}$, de 25 de julho de 2001. Dispõe a Política Estadual de Recursos Hídricos, institui o Sistema Estadual de Gerenciamento de Recursos Hídricos e dá outras providências. $<$ http://bancodeleis.alepa.pa.gov.br:8080/arquivos/lei6381 2016 81559.pdf>. Acesso em: 16 jul. 2020.

ALEPA. Decreto $\mathbf{n}^{\mathbf{0}} \mathbf{2 7 6}$, de 2 de dezembro de 2011. Regulamenta o Conselho Estadual de Recursos Hídricos, substituindo o Decreto $\mathrm{n}^{\circ}$ 2.070, de 20 de fevereiro de 2006. Disponível

em: 
< http://bancodeleis.alepa.pa.gov.br:8080/arquivos/lei276 2011 21188.pdf $>$. Acesso em: 16 jul. 2020.

ARNT, R. A; SCHWARTZMAN, S. Um artifício orgânico. Transição na Amazônia e ambientalismo. Rio de Janeiro: Rocco, 1992.

ANTUNES, R. O privilégio da servidão. O novo proletariado de serviços na era digital. São Paulo: Boitempo, 2018.

AGROPALMA. Relatório de Sustentabilidade AGROPALMA 2017. <https://www.agropalma.com.br/arquivos/relatorios/BX2 PT AGP 016 Relatorio sust entabilidade REVISADO 29jan19-1549629900.pdf>. Acesso em: 16 jul. 2020.

ALVES, S. A. O. [et al.]. Indicadores de sustentabilidade da agroindústria do dendê no estado do Pará. In: Energ. Agric., Botucatu, v. 28, n. 4, p. 240-246, out./dez. 2013. Disponível em: <http://revistas.fca.unesp.br/index.php/energia/article/view/953 > . Acesso em: 16 jul. 2020.

BARCELOS, E.; PACHECO, A. R.; MÜlLER, A. A., VIEGAS, I.; TINOCO, P. B. Dendê: informações básicas para seu cultivo. Belém: Embrapa Amazônia OrientalDocumentos (INFOTECA-E), $1987 . \quad$ Disponível em: < https://www.infoteca.cnptia.embrapa.br/bitstream/doc/383839/1/BelemDoc1.pdf>.

Acesso em: 16 jul. 2020.

BERTONE, M. V. A importância do Programa de Produção Sustentável de Palma de Óleo: produtividade e sustentabilidade. Agroenergia em Revista (Palma para o dendê), v. 2, n. 2, p. 6-7, maio 2011. Disponível em: $<$ https://ainfo.cnptia.embrapa.br/digital/bitstream/item/54887/1/2011AP39.pdf $>$.

Acesso em: 16 jul. 2020.

BIOPALMA. Relatório de Sustentabilidade BIOPALMA DA AMAZÔNIA S.A. 2016. $<$ https://www.biopalma.com.br/pdf/relatorio-sustentabilidade-2016.pdf $>$. Acesso em: 16 jul. 2020.

BRAGA, L. M. M; FERRÃO, A. M. de A. A gestão dos recursos hídricos na França e no Brasil com foco nas bacias hidrográficas e seus sistemas territoriais. Labor \& Engenho, v. 9, n. 4, p. 19-33, out./dez. 2015. Disponível em: $<$ https://periodicos.sbu.unicamp.br/ojs/index.php/labore/article/view/8642229/pdf>.

Acesso em: 16 jul. 2020.

BRASIL. Lei $\mathbf{n}^{\circ} \mathbf{9 . 4 3 3}$, de 8 de janeiro de 1997. Institui a Política Nacional de Recursos Hídricos, cria o Sistema Nacional de Gerenciamento de Recursos Hídricos [...]. Disponível em: $\quad$ https://www2.camara.leg.br/legin/fed/lei/1997/lei-9433-8-janeiro-1997-374778publicacaooriginal-1-pl.html>. Acesso em: 16 jul. 2020.

CHAUÍ, M. Cultura e democracia: o discurso competente e outras falas. 9. ed. São Paulo: Cortez, 1981.

CARVALHO, A. C. A.; NAHUM, J. S. Dendeicultura e migração em Tomé-Açu (Pará): o caso da Vila Forquilha. InterEspaço: Revista de Geografia e Interdisciplinaridade, Grajaú-MA, v. 5, n. 16, p. 01-23, 2019. Disponível em: 
$<$ http://www.periodicoseletronicos.ufma.br/index.php/interespaco/article/view/8002>. Acesso em: 16 jul. 2020.

FURLAN JR, J.; KALTNER, F.J.; AZEVEDO, G.F.P.; CAMPOS, I.A. Biodiesel: Porque têm que ser dendê. Belém, PA: Embrapa Amazônia Oriental, 2006.

GOVERNO DO ESTADO DO PARÁ. Decreto publicado em 28 de fevereiro de 2013, Diário Oficial $\mathbf{n}^{\mathbf{0}}$. 32346, Caderno $\mathrm{n}^{\circ}$. 02, p. 05-06. Disponível em: < https://www.semas.pa.gov.br/wpcontent/uploads/2012/09/DECRETO DE NOME ACAO DOS CONSELHEIROS SEGUNDO MANDATO.pdf $>$. Acesso em: 16 jul. 2020.

GOVERNO DO ESTADO DO PARÁ. Resolução n⿳0 $\mathbf{1 6}$, de 23 de novembro de 2018. Estabelece diretrizes para a formação e funcionamento dos Comitês de Bacias Hidrográficas, no âmbito do Estado do Pará. (2018a). Disponível em: $<$ https://www.semas.pa.gov.br/2018/11/28/resolucao-no-16-de-23-de-novembro-de2018/>. Acesso em: 16 jul. 2020.

GOVERNO DO ESTADO DO PARÁ. Resolução n $\mathbf{n}^{\mathbf{1}} \mathbf{1 7}$, de $\mathbf{0 5}$ de novembro de 2018. Regimento interno do Conselho Estadual de Recursos Hídricos do Estado do Pará. (2018b). Disponível em: < https://www.semas.pa.gov.br/2019/03/25/resolucao-no-17-de05-de-novembro-de-2018/>. Acesso em: 16 jul. 2020.

GOVERNO DO ESTADO DO PARÁ. Resolução no 18, 27 de dezembro de 2018. Dispõe sobre as diretrizes de elaboração do Plano Estadual de Capacitação em Recursos Hídricos. (2018c). Disponível em: < https://www.semas.pa.gov.br/2019/01/11/resolucaono-18-27-de-dezembro-de-2018/>. Acesso em: 16 jul. 2020.

G1PA. Moradores de Ourém interditam PA-124 e protestam contra vazamento de resíduos em rio da região, 03 jan. 2020. Disponível em: $<$ https://g1.globo.com/pa/para/noticia/2020/10/03/moradores-de-ourem-interditampa-124-e-protestam-contra-vazamento-de-residuos-em-rio-da-regiao.ghtml >. Acesso em 05 out. 2020.

FRIAS, R. Pará institui primeiro Comitê de Bacia Hidrográfica. Agência Pará. 04 set. 2019, 17h22, Atualizada em 04 set. 2019, 18h32. Disponível em: < https://agenciapara.com.br/noticia/14775/>. Acesso em: 16 jul. 2020.

HOEKSTRA, A. Y; HUNG, P. G. Virtual water trade: a quantification of virtual water flows between nations in relation to international crop trade. Value of water research report series, n. 11, September 2002. Disponível em:

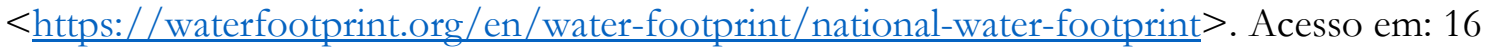
jul. 2020.

KALTNER, F. J.; FURLAN JÚNIOR, J.; DA SILVA, E. B.; VEIGA, A. S.; VAZ, J. D. C. Viabilidade técnica e econômica de produção de ésteres de óleo de palma, para utilização como substituto de óleo diesel, na Amazônia. Belém: Embrapa Amazônia Oriental-Documentos (INFOTECA-E), 2004. Disponível em: $<$ https://www.infoteca.cnptia.embrapa.br/bitstream/doc/408467/1/OrientalDoc193.PD F>. Acesso em: 16 jul. 2020.

MARTINS, J. S. O poder do atraso. Ensaios de sociologia da história lenta. 2. ed. São Paulo: Hucitec, 1999. 
MÜLlER, A. A., ALVES R. M. A dendeicultura na Amazônia brasileira. Belém: Embrapa Amazônia Oriental-Documentos (INFOTECA-E), 1997. Disponível em: < http://www.infoteca.cnptia.embrapa.br/bitstream/doc/374987/1/CPATUDoc91.pdf>. Acesso em: 16 jul. 2020.

NAHUM, J. S; SANTOS, C. B. dos. Dendê para quê? Dendê para quem? A ideologia da fronteira na Amazônia paraense. Rev. NERA, Presidente Prudente, v. 21, n. 42, p. 113 134, 2018a. Disponível em: <http://revista.fct.unesp.br/index.php/nera/article/viewFile/5689/4268>. Acesso em: 16 jul. 2020.

NAHUM, J. S; SANTOS, C. B. do; SANTOS, L. S. Dendeicultura e Biodiesel na Amazônia paraense. Estudos Geográficos, Rio Claro, v. 16, n. 1, p. 60-74, jan./jun. 2018 b.

<http://www.periodicos.rc.biblioteca.unesp.br/index.php/estgeo/article/view/12854/864 5 >. Acesso em: 16 jul. 2020.

NAHUM, J. S; SANTOS, C. B. do. Impactos socioambientais da dendeicultura em comunidades tradicionais na Amazônia paraense. ACTA Geográfica, Boa Vista, Ed. Esp. Geografia Agrária, p. 63-80, 2013. Disponível em: <https://revista.ufrr.br/actageo/article/view/1953/1252>. Acesso em: 16 jul. 2020.

NAHUM, J. S; BASTOS, C. S. Dendeicultura e descampesinização na Amazônia paraense. CAMPO-TERRITÓRIO: revista de geografia agrária, v. 9, n. 17, p. 469-485, abr. 2014. em: <http://www.seer.ufu.br/index.php/campoterritorio/article/view/23628/14394>. Acesso em: 16 jul. 2020.

REDAÇÃO. EXCLUSIVO - Agropalma despeja dendê e contamina Rio Acará. Ver-ofato, 8 out. 2019. Disponível em: < https://ver-o-fato.com.br/exclusivo-agropalmadespeja-dende-e-contamina-rio-acara/>. Acesso em: 16 jul. 2020.

SILVA, J. M. L. da [et al.]. Macrozaneamento Pedoclimático para a Cultura do Dendezeiro no Estado do Pará. Belém: Embrapa (INFOTECA-E), 2003. Disponível em:

< https://www.infoteca.cnptia.embrapa.br/infoteca/bitstream/doc/408073/1/OrientalDo c158.PDF>. Acesso em: 16 jul. 2020.

THOMAZ JUNIOR, A. Dinâmica territorial do agrohidronegócio e os desdobramentos para o trabalho. OKARA: Geografia em debate, v. 6, n. 1, p. 7-31, 2012. Disponível em: $<$ https://periodicos.ufpb.br/ojs/index.php/okara/article/view/13603>. Acesso em: 16 jul. 2020.

THOMAZ JUNIOR, A. Degradação sistêmica do trabalho no agrohidronegócio. Mercator, Fortaleza, v. 16, e16020, 2017. Disponível em:

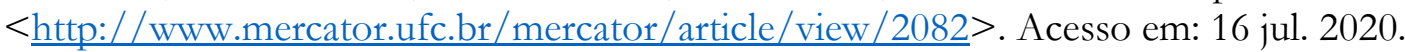

VASCONCELOS, T. C. C. D. Análise dos índices de erosividade a partir de dados de precipitação de postos pluviométricos do Município de João Pessoa-PB. 2013. $51 \mathrm{f}$. Trabalho de Conclusão de Curso (Geociências) - Universidade Federal da Paraíba, João Pessoa, 2013. Disponível em:

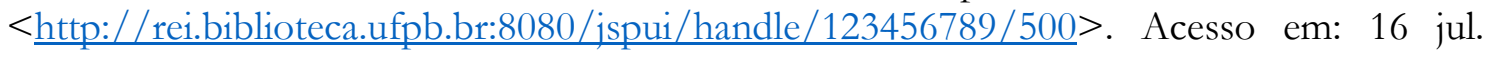
2020 . 
VEIGA, A.; SINIMBÚ, S.; RAMOS, E. Sistema de adubação do dendezeiro por reposição de nutrientes exportados pelo cacho. Belém: DENPASA, 2001.

VENTURIERI, A. V. [et al.]. Possibilidades e limitações para a inserção da agricultura familiar no desenvolvimento e produção de bioenergia derivada da palma-de-óleo no estado do Maranhão. 2017. Disponível em: $<$ https://ainfo.cnptia.embrapa.br/digital/bitstream/item/159869/1/20170515-170515trabalho-vale-ecodebate-2017-1a.pdf>. Acesso em: 16 jul. 2020.

\section{Como citar este artigo:}

\section{ABNT}

NAHUM, J. S.; SANTOS, L. S.; SANTOS, C. B. Usos e abusos dos recursos hídricos pela dendeicultura na Amazônia paraense. InterEspaço: Revista de Geografia e Interdisciplinaridade, v. 6, e202010, 2020. Disponível em: <http://dx.doi.org/10.18764/2446-6549.e202010>. Acesso em: 25 jan. 2020.

\section{APA:}

Nahum, J. S., Santos, L. S., \& Santos, C. B. (2020). Usos e abusos dos recursos hídricos pela dendeicultura na Amazônia paraense. InterEspaço: Revista de Geografia e Interdisciplinaridade, v. 6, e202010. Recuperado em 25 janeiro, 2020, de http://dx.doi.org/10.18764/2446-6549.e202010

\section{cc) creative}

This is an open access article under the CC BY Creative Commons 4.0 license.

Copyright (C) 2020, Universidade Federal do Maranhão.

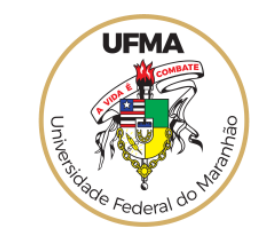

